\title{
SOFTWARE REQUIREMENT SPECIFICATION SISTEM INFORMASI MANAJEMEN DAN GEOGRAFIS PEMETAAN SUMBER DAYA AIR
}

\author{
Yudhi Kurniawan ${ }^{1)}$, Paulus Lucky TI $^{2)}$ \\ ${ }^{1)}$ Program Studi Sistem Informasi, Fakultas Sains Dan Teknologi, ${ }^{2)}$ Program Studi Teknik Informatika, \\ Fakultas Sains Dan Teknologi, Universitas Ma Chung, Villa Puncak Tidar N-01 Malang, Indonesia \\ email : yudhi.kurniawan@machung.ac.id ${ }^{1)}$,paulus.lucky@machung.ac.id $\left.{ }^{2}\right)$
}

\begin{abstract}
Abstrak
Informasi Visual pada beberapa tahun ini menjadi trend dikalangan pengembang sistem visualisasi informasi dalam bentuk multimedia menjadi hal yang sudah tidak asing lagi bagi dunia teknologi informasi khususnya di bidang elektronik marketing, visual bukan hanya bisa dilihat dalam bentuk gambar bergerak 3 dimensi melainkan informasi yang mengandung unsur geografis dan keruangan juga merupaka visualisasi informasi yang cukup relevan digunakan untuk sebuah perencanaan, dengan melakukan mapping dan memetakan letak serta posisi bagi seorang eksekutif pada tataran pemerintahan merupakan salah satu tools yang sangat berguna, karena dengan memetakan suatu informasi maka dapat diketahui sebaran pola dan analisa ruang untuk pengambilan keputusan. Begitupun juga dengan Sumber Daya Air di mana pemetaan letak dan posisi serta pengelolaannya menjadi mutlak dibutuhkan untuk menjamin ketersediaan air bagi masyarakat, identifikasi dan inventarisasi sumber daya air didukung dengan validitas data penanggung jawab pada kelompok hippam serta monitoring pemeliharaan terhadap aset atau komponen pada infrastruktur dan kelengkapan sumber daya air perlu direncanakan dalam setiap anggaran belanja dan tentunya juga memperhatikan pemerataan pembangunan dengan tujuan untuk menjamin hajat hidup masyarakat. Dengan Sistem Informasi Manajemen Dan Geografis Pemetaan Sumber Daya Air menjadi sebuah early warning system bagi aktifitas pengelolaan dan manajemen Sumber Daya Air identifikasi awal dan dokumentasi kebutuhan peranglat lunak menjadi standar pengembangan Sistem Informasi dalam skala enterprise sesuai dengan standar IEEE 830-1998.
\end{abstract}

\section{Kata Kunci :}

Pengelolaan sumber daya air, identifikasi dan inventarisasi, pemetaan, standar pengembangan sistem, spesifikasi, IEEE 830-1998.

\begin{abstract}
In recent years, the visual information has become a trend among the developers of information systems. The visualization has become a familiar thing for the world of information technology, especially in the field of electronic marketing. The visual information not only be seen in 3 dimension moving images but information that contains geographical elements. The space in geographical is also a visualization of information that relevant to be used for planning with mapping the location and position of an executive government level. Mapping is one of the tools that's very useful, because by mapping an information it can be known the distribution of patterns and analysis of space for decision-making. Likewise with Water Resources, where mapping of the location and position and management is absolutely necessary to ensure the availability of water for the community, identification and inventory of water resources supported by the validity of data responsible for hippam groups and monitoring maintenance of assets or components in infrastructure and completeness of resources Water power needs to be planned in every budget and of course also pay attention to equitable development with the aim of ensuring the livelihood of the community. With the Management and Geographical Information System for Mapping Water Resources into an early warning system for management activities and management of Water Resources, initial identification and documentation of the need for soft warfare have become standards for developing Information Systems on an enterprise scale in accordance with the IEEE 830-1998 standard.
\end{abstract}

\section{Keywords :}

Management of water resources, determine and inventory, mapping, standard system development, specifications, IEEE 830-1998. 


\section{PENDAhuluan}

Terlepas dari tingginya potensi sumber daya air, sumber daya air permukaan di Indonesia mengalami kekurangan selama musim kemarau, namun terjadi banjir selama musim hujan terutama di beberapa daerah. Meskipun Indonesia memiliki curah hujan yang berlimpah, dengan rata-rata nasional lebih dari $2.500 \mathrm{~mm} /$ tahun, namun terjadi perbedaan yang sangat besar di daerah tertentu di Indonesia. Hal ini terjadi berkisar dari daerah-daerah yang sangat kering di Nusa Tenggara, Maluku dan Sulawesi bagian dari Kepulauan (kurang dari 1.000 $\mathrm{mm}$ ) dan yang sangat basah di beberapa bagian daerah Papua, Jawa, dan Sumatra (lebih dari $5.000 \mathrm{~mm}$ ). Mengingat tantangan yang dihadapi oleh sektor sumber daya air dan sektor irigasi di abad ke-21 dan reformasi sektor publik yang lebih memperhatikan aspirasi rakyat, Pemerintah Indonesia telah memulai program reformasi bidang sumber daya air yang meliputi aspek kebijakan, aspek kelembagaan, aspek legislatif dan peraturan, dan kebijakan konservasi sumber daya air telah mendapat bagian yang substansial dalam agenda reformasi.

Didalam Undang-Undang Republik Indonesia Nomor 7 Tahun 2004 Tentang Sumber Daya Air dijelaskan; Sumber daya air merupakan karunia Tuhan Yang Maha Esa yang memberikan manfaat untuk mewujudkan kesejahteraan bagi seluruh rakyat Indonesia dalam segala bidang. Sejalan dengan Pasal 33 ayat (3) Undang-Undang Dasar Negara Republik Indonesia Tahun 1945, undang-undang ini menyatakan bahwa sumber daya air dikuasai oleh negara dan dipergunakan untuk sebesar-besar kemakmuran rakyat secara adil. Atas penguasaan sumber daya air oleh negara dimaksud, negara menjamin hak setiap orang untuk mendapatkan air bagi pemenuhan kebutuhan pokok sehari-hari dan melakukan pengaturan hak atas air.

Pengelolaan Sumber Daya Air merupakan kewenangan Pemerintah Daerah yang diatur sesuai dengan Peraturan Kementrian Pekerjaan Umum di mana salah satu fungsinya adalah Perencanaan teknis, pembangunan, pemeliharaan, rehabilitasi, penyediaan sarana prasarana dan perawatan serta pengawasan peralatan dan perbekalan dibidang cipta karya, tata ruang, kebersihan dan pertamanan.

Dukungan penggunaan Teknologi Informasi khususnya Sistem Informasi dalam adopsi manajemen dan penambahan fungsi geografis untuk pemetaan Sumber Daya Air diperlukan guna mempercepat pengolahan informasi dan mempermudah pengambilan keputusan berdasarkan informasi dan pengolahan data yang dapat disajikan dalam bentuk digital dan bisa diakses di mana saja dan kapan saja terutama bagi pihak eksekutif dan pimpinan.

Maka dari itu standar pengembangan sistem informasi dibutuhkan sesuai dengan standar yang ada dengan dimulai membuat Dokumen Analisa Kebutuhan Perangkat Lunak Sistem Informasi Manajemen Dan Geografis Pemetaan Sumber Daya Air yang komprehensif, tidak ambigu, dan mudah dimengerti untuk dapat dilanjutkan dalam tahapan desain di fase berikutnya.

\section{METODE / ALGORITMA}

Dalam pengerjaan penelitian ini digunakan metode SDLC. Metode SDLC adalah metode yang menggunakan pendekatan sistem yang disebut pendekatan air terjun (waterfall approach) di mana setiap tahapan sistem akan dikerjakan secara berurut menurun dari perencanaan, analisa, desain, implementasi, dan perawatan [2]. Penggunaan standarpengembangan sistem sangat jarang di gunakan di mana untuk mengembangkat perangkat lunak pada fase analisa bisa menggunakan standar yang sudah di terjemahkan dari best practices yang sudah yaitu sebuah standar dalam bentuk Dokumentasi tentang Spesifikasi kebutuhan Perangkat Lunak yang sesuai dengan standar IEEE 830-1998 tentang Software Requirement Specification[7]. 


\subsection{Analisa Kebutuhan}

Sistem Informasi ini adalah sebuah sistem yang mengolah data dan informasi tentang sumber daya air dengan jenis dan kategorinya baik itu sebagai bangunan utama dari sumber daya air itu sendiri dan bangunan pelengkap, sarana, parasarana dan kelengkapan yang lain di sekitarnya dengan tujuan adalah inventarisasi sumber daya air dan sekaligus monitoring dan pemeliharaan yang berguna untuk mempermudah berbasis pada manajemen pengelolaan sumber daya air dan pemetaan letak sumber daya secara digital guna mendukung pengambilan keputusan dengan menjaga ketersediaan air dan kelestarian sumber daya air, alam sekitarnya dan hajat hidup masyarakat

Tabel 1 Tabel Definisi Kebutuhan User Fungsional Dan Non Fungsional

\begin{tabular}{|c|c|c|c|}
\hline \multirow{2}{*}{ No } & \multirow{2}{*}{ Deskripsi Kebutuhan } & \multicolumn{2}{|c|}{ Fungsional } \\
\hline & & System & User \\
\hline 1. & $\begin{array}{l}\text { Sistem dapat menampilkan sebaran letak sumber daya } \\
\text { air dengan jenis, kategori dan juga posisi dengan } \\
\text { attribute data yang lain ditampilkan secara map dan } \\
\text { geografi. }\end{array}$ & $\mathrm{V}$ & \\
\hline 2. & $\begin{array}{l}\text { Pengguna dapat menggunakan sistem dengan terlebih } \\
\text { dahulu login dan sesuai dengan sistem rule yang ada dan } \\
\text { di definisikan untuk setiap pengguna. }\end{array}$ & & V \\
\hline 3. & $\begin{array}{l}\text { Sistem menampilkan halaman dan menu sesuai dengan } \\
\text { rule dan pengaturan user serta hak akses yang dimiliki } \\
\text { oleh pengguna yang sudah di tentukan oleh } \\
\text { administrator. }\end{array}$ & & V \\
\hline 4. & $\begin{array}{l}\text { Pengguna dapat melakukan interaksi dengan sistem } \\
\text { sesuai dengan menu yang tampil dan tersedia untuk } \\
\text { setiap pengguna }\end{array}$ & & V \\
\hline 5. & $\begin{array}{l}\text { Pengguna dapat melakukan input data sesuai dengan } \\
\text { fungsi yang ada dan sesuai dengan fungsi bisnis yang } \\
\text { ada di setiap are fungsi bisnis seperti mastering, } \\
\text { transaksional, reporting dan juga view/preview } \\
\text { informasi. }\end{array}$ & V & \\
\hline 6. & $\begin{array}{l}\text { Pengguna dapat melakukan penambahan data, } \\
\text { perubahan data dan juga melihat data dalam kategori } \\
\text { master data pada modul master data management. }\end{array}$ & $\mathrm{V}$ & \\
\hline 7. & $\begin{array}{l}\text { Pengguna dapat melakukan penambahan data, } \\
\text { perubahan data dan juga melihat data transaksional } \\
\text { untuk sumber daya air dengan jenis dan kategori } \\
\text { bendungan/waduk, danau, wilayah sungai, rawa, } \\
\text { pengaman pantai dan irigasi. }\end{array}$ & & V \\
\hline 8. & $\begin{array}{l}\text { Pengguna dapat melakukan penambahan data baik yang } \\
\text { bersifat spasial berupa latitude dan longitude dengan tipe } \\
\text { point, line dan juga polygon serta data lain yang bersifat } \\
\text { atribut dan kelengkapan data. }\end{array}$ & & V \\
\hline
\end{tabular}


URL : https://jurnal.machung.ac.id/index.php/kurawal

Tabel 1 Tabel Definisi ... (Lanjutan)

\begin{tabular}{|c|c|c|c|}
\hline \multirow{2}{*}{ No } & \multirow{2}{*}{ Deskripsi Kebutuhan } & \multicolumn{2}{|c|}{ Fungsional } \\
\hline & & System & User \\
\hline 9. & $\begin{array}{l}\text { Pengguna dapat melakukan penambahan data, } \\
\text { perubahan data untuk sumber daya air dengan jenis } \\
\text { waduk/bendungan dengan detail data kecamatan, } \\
\text { kelurahan, nama waduk, kedalaman, tahun di bangun, } \\
\text { gambar, letak posisi dan keterangan. }\end{array}$ & & V \\
\hline 10. & $\begin{array}{l}\text { Pengguna dapat melakukan penambahan data, } \\
\text { perubahan data untuk sumber daya air dengan jenis } \\
\text { irigasi dengan nama irigasi, panjang saluran bangunan } \\
\text { pembagi pintu, panjang saluran primer, panjang saluran } \\
\text { sekunder, luas, tahun di bangun, gambar, letak posisi } \\
\text { dan keterangan. }\end{array}$ & & $\mathrm{V}$ \\
\hline 11. & $\begin{array}{l}\text { Pengguna dapat melakukan penambahan data, } \\
\text { perubahan data untuk sumber daya air dengan jenis rawa } \\
\text { dengan nama rawa, panjang saluran bangunan pembagi } \\
\text { pintu, panjang saluran primer, panjang saluran sekunder, } \\
\text { luas, tahun di bangun, gambar, letak posisi dan } \\
\text { keterangan. }\end{array}$ & & $\mathrm{V}$ \\
\hline 12. & $\begin{array}{l}\text { Pengguna dapat melakukan penambahan data, } \\
\text { perubahan data untuk sumber daya air dengan jenis } \\
\text { irigasi dengan nama sungai, nama das, ordo, gambar, } \\
\text { letak posisi dan keterangan. }\end{array}$ & & $\mathrm{V}$ \\
\hline 13. & $\begin{array}{l}\text { Pengguna dapat melakukan penambahan data, } \\
\text { perubahan data untuk sumber daya air dengan jenis } \\
\text { embung dengan nama embung, genangan volume, tahun } \\
\text { di bangun, elevasi dasar embung, genangan luas (ha), } \\
\text { tahun di bangun, elevasi dasar embung, genangan luas } \\
\text { (ha), kondisi, elevasi puncak, elevasi MA normal, } \\
\text { dimensi tinggi, dimensi lebar, gambar, letak posisi dan } \\
\text { keterangan. }\end{array}$ & & $\mathrm{V}$ \\
\hline 14. & $\begin{array}{l}\text { Pengguna dapat melakukan penambahan data } \\
\text { pengamatan terhadap data debit/volume air dengan filter } \\
\text { sungai, pos hidroklimatologi, tentang data lebar, luas, } \\
\text { kecepatan, tma dan debit air dari transaksi bersifat } \\
\text { harian. }\end{array}$ & & V \\
\hline 15. & $\begin{array}{l}\text { Pengguna dapat melakukan penambahan data } \\
\text { pengamatan terhadap data debit/volume air, curah hujan, } \\
\text { dengan filter sungai, pos hidroklimatologi, dari transaksi } \\
\text { bersifat harian. }\end{array}$ & & V \\
\hline 16. & $\begin{array}{l}\text { Pengguna dapat melakukan penambahan data } \\
\text { pengamatan terhadap debit sungai dengan filter sungai } \\
\text { dan pos hidroklimatologi dengan data intake kiri, intake } \\
\text { kanan dan debit air. }\end{array}$ & & $\mathrm{V}$ \\
\hline
\end{tabular}


URL : https://jurnal.machung.ac.id/index.php/kurawal

Tabel 1 Tabel Definisi ... (Lanjutan)

\begin{tabular}{|c|c|c|c|}
\hline \multirow{2}{*}{ No } & \multirow{2}{*}{ Deskripsi Kebutuhan } & \multicolumn{2}{|c|}{ Fungsional } \\
\hline & & System & User \\
\hline 17. & $\begin{array}{l}\text { Sistem dapat menyimpan data dari pengguna yang } \\
\text { melakukan penambahan data, perubahan data dan juga } \\
\text { melihat data dalam kategori master data pada modul } \\
\text { master data management. }\end{array}$ & $\mathrm{V}$ & \\
\hline 18. & $\begin{array}{l}\text { Sistem dapat menyimpan data dari pengguna yang } \\
\text { melakukan penambahan data, perubahan data dan juga } \\
\text { melihat data transaksional untuk sumber daya air dengan } \\
\text { jenis dan kategori bendungan/waduk, danau, wilayah } \\
\text { sungai, rawa, pengaman pantai dan irigasi. }\end{array}$ & $\mathrm{V}$ & \\
\hline 19. & $\begin{array}{l}\text { Sistem dapat menyimpan data dari pengguna yang } \\
\text { melakukan penambahan data baik yang bersifat spasial } \\
\text { berupa latitude dan longitude dengan tipe point, line dan } \\
\text { juga polygon serta data lain yang bersifat atribut dan } \\
\text { kelengkapan data. }\end{array}$ & $\mathrm{V}$ & \\
\hline 20. & $\begin{array}{l}\text { Sistem dapat menyimpan data dari pengguna yang } \\
\text { melakukan penambahan data, perubahan data untuk } \\
\text { sumber daya air dengan jenis waduk/bendungan dengan } \\
\text { detail data kecamatan, kelurahan, nama waduk, } \\
\text { kedalaman, tahun di bangun, gambar, letak posisi dan } \\
\text { keterangan. }\end{array}$ & $\mathrm{V}$ & \\
\hline 21. & $\begin{array}{l}\text { Sistem dapat menyimpan data dari pengguna yang } \\
\text { melakukan penambahan data, perubahan data untuk } \\
\text { sumber daya air dengan jenis irigasi dengan nama } \\
\text { irigasi, panjang saluran bangunan pembagi pintu, } \\
\text { panjang saluran primer, panjang saluran sekunder, luas, } \\
\text { tahun di bangun, gambar, letak posisi dan keterangan. }\end{array}$ & $\mathrm{V}$ & \\
\hline 22. & $\begin{array}{l}\text { Sistem dapat menyimpan data dari pengguna yang } \\
\text { melakukan penambahan data, perubahan data untuk } \\
\text { sumber daya air dengan jenis rawa dengan nama rawa, } \\
\text { panjang saluran bangunan pembagi pintu, panjang } \\
\text { saluran primer, panjang saluran sekunder, luas, tahun di } \\
\text { bangun, gambar, letak posisi dan keterangan. }\end{array}$ & $\mathrm{V}$ & \\
\hline 23. & $\begin{array}{l}\text { Sistem dapat menyimpan data dari pengguna yang } \\
\text { melakukan penambahan data, perubahan data untuk } \\
\text { sumber daya air dengan jenis irigasi dengan nama } \\
\text { sungai, nama das, ordo, gambar, letak posisi dan } \\
\text { keterangan. }\end{array}$ & $\mathrm{V}$ & \\
\hline 24. & $\begin{array}{l}\text { Sistem dapat menyimpan data dari pengguna yang } \\
\text { melakukan penambahan data, perubahan data untuk } \\
\text { sumber daya air dengan jenis embung dengan nama } \\
\text { embung, genangan volume, tahun di bangun, elevasi. }\end{array}$ & $\mathrm{V}$ & \\
\hline
\end{tabular}


URL : https://jurnal.machung.ac.id/index.php/kurawal

Tabel 1 Tabel Definisi ... (Lanjutan)

\begin{tabular}{|c|c|c|c|}
\hline \multirow{2}{*}{ No } & \multirow{2}{*}{ Deskripsi Kebutuhan } & \multicolumn{2}{|c|}{ Fungsional } \\
\hline & & System & User \\
\hline & $\begin{array}{l}\text { dasar embung, genangan luas (ha), tahun di bangun, } \\
\text { elevasi dasar embung, genangan luas (ha), kondisi, } \\
\text { elevasi puncak, elevasi MA normal, dimensi tinggi, } \\
\text { dimensi lebar, gambar, letak posisi dan keterangan }\end{array}$ & & \\
\hline 25. & $\begin{array}{l}\text { Sistem dapat menyimpan data dari pengguna yang } \\
\text { melakukan penambahan data pengamatan terhadap data } \\
\text { debit/volume air dengan filter sungai, pos } \\
\text { hidroklimatologi, tentang data lebar, luas, kecepatan, } \\
\text { tma dan debit air dari transaksi bersifat harian. }\end{array}$ & $\mathrm{V}$ & \\
\hline 26. & $\begin{array}{l}\text { Sistem dapat menyimpan data dari pengguna yang } \\
\text { melakukan penambahan data pengamatan terhadap data } \\
\text { debit/volume air, curah hujan, dengan filter sungai, pos } \\
\text { hidroklimatologi, dari transaksi bersifat harian. }\end{array}$ & $\mathrm{V}$ & \\
\hline 27. & $\begin{array}{l}\text { Sistem dapat menyimpan data dari pengguna yang } \\
\text { melakukan penambahan data pengamatan terhadap debit } \\
\text { sungai dengan filter sungai dan pos hidroklimatologi } \\
\text { dengan data intake kiri, intake kanan dan debit air. }\end{array}$ & $\mathrm{V}$ & \\
\hline 28. & $\begin{array}{l}\text { Pengguna dapat menampilkan laporan dan melakukan } \\
\text { cetak laporan terkait debit air secara periodik }\end{array}$ & & V \\
\hline 29. & $\begin{array}{l}\text { Sistem dapat menampilkan laporan dan melakukan cetak } \\
\text { laporan terkait debit air secara periodik }\end{array}$ & $\mathrm{V}$ & \\
\hline 30. & $\begin{array}{l}\text { Pengguna dapat melakukan logout atau keluar dari } \\
\text { sistem sesuai dengan prosedur dan langkah keluar dari } \\
\text { sistem }\end{array}$ & & $\mathrm{V}$ \\
\hline 31. & $\begin{array}{l}\text { Sistem dapat melakukan logout dari sistem sesuai } \\
\text { dengan pengguna atau interaksi pengguna. }\end{array}$ & $\mathrm{V}$ & \\
\hline 32. & $\begin{array}{l}\text { Pengguna dapat melakukan inventarisasi letak sumber } \\
\text { daya air dalam setiap area atau kawasan yang sudah } \\
\text { ditentukan, dengan inventarisasi data terkait } \\
\text { kelengkapan sumber daya air dan penanggung } \\
\text { jawabnya. }\end{array}$ & & V \\
\hline 33. & $\begin{array}{l}\text { Pengguna dapat melakukan inventarisasi letak kondisi } \\
\text { dan jenis komponan sumber daya air serta distribusinya } \\
\text { sampai ke sambungan rumah (SR). }\end{array}$ & & V \\
\hline 34. & $\begin{array}{l}\text { Sistem dapat menampilkan hasil inventarisasi terkait } \\
\text { sumber daya air sevara spasial dan non spasial sesuai } \\
\text { dengan jenis dan kategori sumber daya air. }\end{array}$ & $\mathrm{V}$ & \\
\hline 35 & $\begin{array}{l}\text { Pengguna dapat melakukan input data pemeliharaan, } \\
\text { secara berkala sesuai dengan data inventarisasi yang ada, } \\
\text { jenis komponen sumber daya air, waktu pelaksanaan } \\
\text { pemeliharaan, besaran biaya yang digunakan. }\end{array}$ & & V \\
\hline
\end{tabular}


URL : https://jurnal.machung.ac.id/index.php/kurawal

Tabel 1 Tabel Definisi ... (Lanjutan)

\begin{tabular}{|c|c|c|c|}
\hline \multirow{2}{*}{ No } & \multirow{2}{*}{ Deskripsi Kebutuhan } & \multicolumn{2}{|c|}{ Fungsional } \\
\hline & & System & User \\
\hline 36. & $\begin{array}{l}\text { Sistem dapat menyimpan data pemeliharaan, sesuai } \\
\text { dengan hasil inventarisasi dan data pemeliharaan yang } \\
\text { sudah diinputkan oleh pengguna. }\end{array}$ & V & \\
\hline 37. & $\begin{array}{l}\text { Sistem dapat menampilkan data spasial dan letak } \\
\text { pemeliharaan yang sudah di lakukan dengan informasi } \\
\text { tentang jenis komponen yang di pelihara, waktu } \\
\text { pemeliharaan, jenis pemeliharaan dan biaya } \\
\text { pemeliharaan. }\end{array}$ & $\mathrm{V}$ & \\
\hline 38. & $\begin{array}{l}\text { Sistem dapat membedakan dan mengkelompokkan } \\
\text { kategori pemeliharaan yang sudah di lakukan. }\end{array}$ & V & \\
\hline 39. & $\begin{array}{l}\text { Sistem dapat menampilkan data history pemeliharaan } \\
\text { pada satu area Hippan dengan detail pemeliharaan dan } \\
\text { informasi lainnya berbasis peta atau spasial. }\end{array}$ & V & \\
\hline 40. & $\begin{array}{l}\text { Sistem dapat menampilan letak pemeliharaan sesuai } \\
\text { dengan kategori komponen yang dipelihara meliputi } \\
\text { pipa, sumur, pompa, bangunan penunjang, sambungan } \\
\text { rumah dan seterusnya. }\end{array}$ & V & \\
\hline 41. & $\begin{array}{l}\text { Sistem dapat memisahkan data pemeliharaan yang } \\
\text { bersifat rutin dan bersifat incidental akibat kerusakan } \\
\text { yang disebabkan oleh bencana alam atau kesalahan } \\
\text { manusia. }\end{array}$ & V & \\
\hline 42. & $\begin{array}{l}\text { Sistem dapat menampilan informasi secara cepat untuk } \\
\text { digunakan pada level executive dalam sebuah sistem } \\
\text { informasi yang terintegrasi. }\end{array}$ & V & \\
\hline 43. & $\begin{array}{l}\text { Sistem dapat memberikan laporan secara periodik dan } \\
\text { berkala terhadap hasil inventarisasi pada HIPPAM yang } \\
\text { sudah di data dalam sistem }\end{array}$ & V & \\
\hline 44. & $\begin{array}{l}\text { Sistem dapat menampilkan sebaran HIPPAM sesaui } \\
\text { dengan lokasi dan menampilkan data administratif } \\
\text { dengan filter sesuai dengan kecamatan dan desa. }\end{array}$ & V & \\
\hline 45. & $\begin{array}{l}\text { Sistem dapat menampilkan sebaran pipa untuk setiap } \\
\text { HIPPAM yang sudah di daftarkan dalam sistem. }\end{array}$ & $\mathrm{V}$ & \\
\hline 46. & $\begin{array}{l}\text { Sistem dapet menyajikan dapat history pemeliharaan } \\
\text { pipa pada masing-masing kecamatan dan keluarahan } \\
\text { yang ada. }\end{array}$ & V & \\
\hline 47. & $\begin{array}{l}\text { Sistem dapat menampilkan sebran hasil inventarisasi } \\
\text { berbasis peta untuk membantu pengambilan keputusan } \\
\text { terkait sebaran pemetaan sumber daya air. }\end{array}$ & V & \\
\hline 48. & $\begin{array}{l}\text { Sistem dapat memberikan data dan informasi pendukung } \\
\text { sebagai perbandingan dari hasil inventarisasi dan } \\
\text { pemeliharaan. }\end{array}$ & $\mathrm{V}$ & \\
\hline
\end{tabular}




\section{Fungsi Dan Perspektif Sistem}

Sistem Informasi Geografis ini adalah sebuah sistem yang digunakan untuk menginventarisir dan memonitoring sumber daya air dan kelengkapannya yang sesuai dengan harapan dan strategi yang sudah ditentukan oleh stakeholder selaku pemilik sistem ini nantinya dengan beberapa batasan sistem :

1. Sistem Informasi Geografis ini digunakan secara online dan berbasis website yang berisikan tentang pengelolaan sumber daya air dan jenisnya serta kelengkapannya.

2. Informasi yang disajikan adalah informasi terkait Sumber Daya Air, Jenis, Sarana Dan Prasarana, serta letak spasial dengan isian data sesuai dengan Peraturan yang berlaku dan kebutuhan pengeloaan sumber daya air dari stakeholder.

3. Pengguna dapat menggunakan Sistem Informasi dan hanya yang sudah terdaftar yang dapat menggunakan melalui moderasi dari pengguna dengan level akses tertinggi, sistem in bukan untuk public melainkan untuk internal stakeholder pengelola sumber daya air sesuai dengan tupoksi dan ketentuan yang berlaku. Jika diperlakukan akses kepada public maka informasi dan data yang ditampilkan sesuai dengan kebijakan yang berlaku.

4. Sistem ini digunakan juga untuk inventarisasi sumber daya air dan sebarannya yang selanjutnya dapat digunakan untuk pemeliharaan sumber daya air yang ada dengan tujuan untuk melakukan manajemen penghematan anggaran, perencanaan kebutuhan anggaran untuk pemeliharaan, pemerataan pembangunan, dan bantuan sosial terhadap ketersedian sumber day air dan air untuk hajat hidup orang banyak.

\section{Karakteristik Pengguna}

Pengguna sistem ini ada beberapa tipe/karakterisitik yaitu :

1. Super Administrator : pengguna dengan level tertinggi terhadap akses dan penggunaan serta penambahan dan perubahan data dari seluruh informasi yang ditampilkan dalam sistem.

2. Operator : adalah level pengguna yang berfungsi dan bertanggung jawab terhadap data dan informasi inventarisasi serta monitoring sumber daya air yang biasanya disebut dengan operator.

3. Guest : adalah level pengguna yang berfungsi dan mempunyai hak serta wewenang menggunakan dan melihat data serta informasi terkait sumber daya air sesuai dengan kebijakan data dan penggunaan sistem.

\section{Batasan}

Batasan-batasan dalam pengembangan perangkat lunak ini adalah:

1. Perangkat lunak ini hanya mencakup pada pengeloaan sumber daya air yang meliputi inventarisasi, pemeliharaan dan pemetaan sebaran sumber daya air.

2. Tujuan dari perangkat lunak ini adalah memberikan kemudahan dalam pengambilan keputusan terhadap perencanaan, pemeliharaan dan inventarisasi sumber daya air dan kelengkapannya untuk dapat di monitoring penggunaan dan ketersediaannya guna pemanfaatan masyarakat.

\section{Asumsi Dan Ketergantungan}

Perangkat lunak ini akan dibangun dengan menggunakan teknologi PHP 5 dan HTML 5 untuk aplikasi web maka untuk sisi server di jalankan dengan sistem operasi windows server/linux, sedangkan sisi client hanya membutuhkan web browser seperti 
Mozilla Firefox, Google Chrome, atau opera, baik dengan platform desktop atau mobile dalam pengaksesannya.

\section{HASIL DAN PEMBAHASAN}

Dalam analisa dilakukan pengelompokan hasil observasi yang ada kedalam Tabel Analisa kebutuhan seperti terlampir pada Tabel 1, dalam tabel analisa kebutuhan di bedakan menjadi 2 hal besar yaitu kebutuhan fungsional dan non fungsional[9], untuk kebutuhan fungsional mempunyai detail antara user dan sistem. Untuk kebutuhan non fungsional terkait dengan kebutuhan atau spesifikasi yang harus di penuhi untuk menjalankan aplikasi.

\section{a. Use Case Diagram}

Diagram ini digunakan untuk menggambarkan hubungan Antara user dengan use case atau proses yang bisa di jalankan oleh user yang ada.

\section{b. Spesifikasi Kebutuhan Non Fungsional}

\section{A. Antarmuka Pemakai}

Pemakai berinteraksi langsung dengan perangkat lunak melalui masukan perintah yang diketikkan langsung dari keyboard atau penggunaan mouse pada link yang suda di sediaka, sedangkan hasil keluaran yang akan ditampilkan langsung ke layar monitor dalam format halaman web

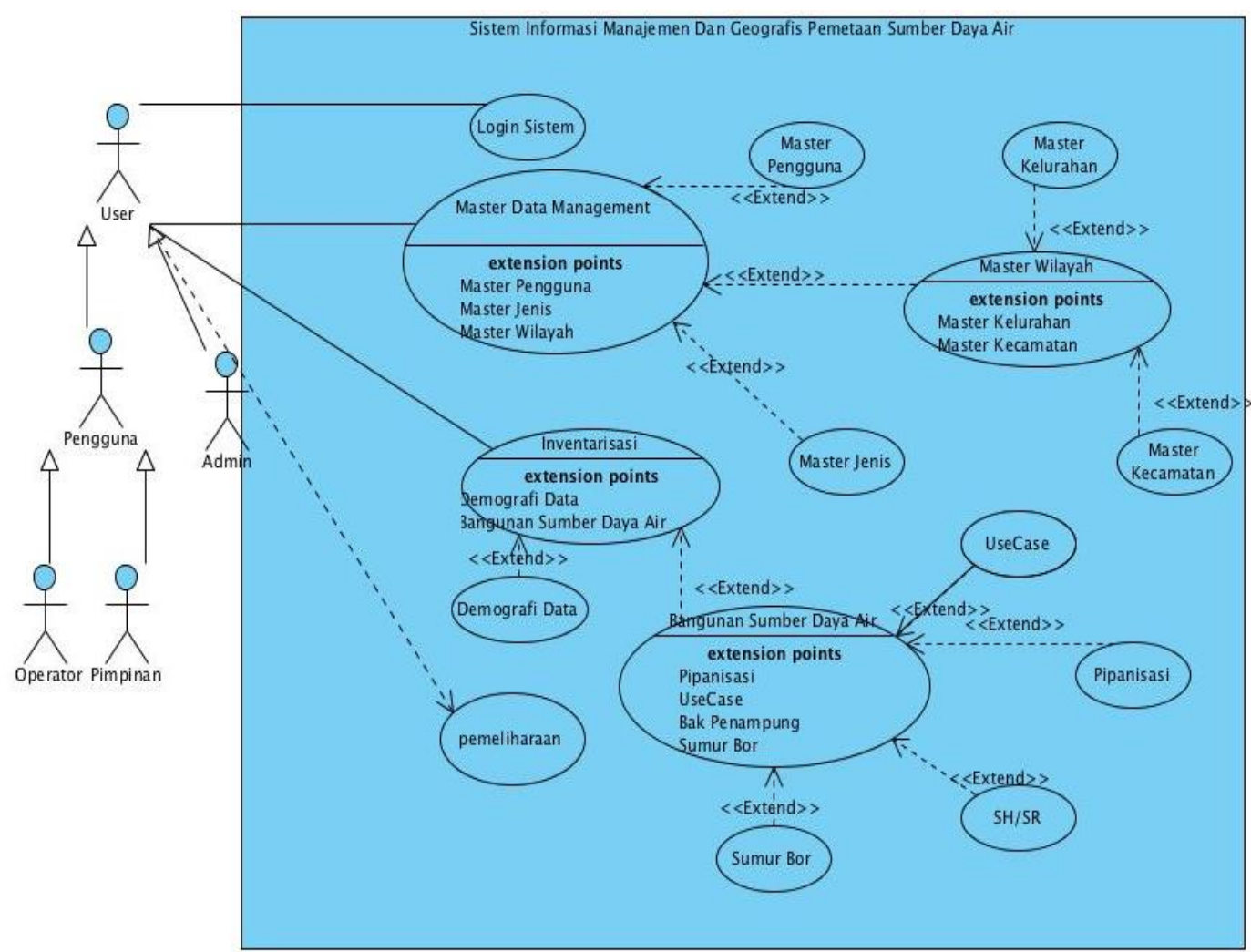

Gambar 1 Use Case Diagram (Spesifikasi Kebutuhan Fungsional) untuk Sistem Informasi Manajemen Dan Geografis Pemetaan Sumber Daya Air 
URL : https://jurnal.machung.ac.id/index.php/kurawal

\section{B. Antarmuka Perangkat Keras}

Antarmuka perangkat keras yang digunakan dalam perangkat lunak ini nanti adalah :

1. PC Desktop/Notebook/Tablet/Smartphone dengan Processore Minimal P4/Snapdragon/yang setara

2. RAM Minimal $512 \mathrm{Mb}$

3. Hardisk/Media Card/MMC/SD Card

4. Monitor

5. Keyboard/Mouse/Touchscreen

C. Antarmuka Perangkat Lunak

Perangkat lunak yang dibutuhkan untuk mengoperasikan perangkat lunak simulasi perhitungan investasi haji adalah :

1. Nama : PHP5.0

\section{Sumber : PHP}

Sebagai tool pengembangan untuk Sistem Informasi Manajemen Dan Geografis Pemetaan Sumber Daya Air

2. Nama : MySQL 5.8

Sumber : Oracle Inc.

Sebagai database yang dibutuhkan dalam mengoperasikan aplikasi Sistem Informasi Manajemen Dan Geografis Pemetaan Sumber Daya Air

3. Nama : Google Chrome

Sumber : Google inc

Sebagai browser internet bagi client.

4. Nama : Apache Web Server/Nginx

Sumber : Apache Foundation

Sebagai web server

\section{c. Spesifikasi Kebutuhan Data}

Dari hasil use case diagram serta detail spesifikasi yang sudah dibuat maka langkah selanjutnya adalah membuat struktur model atau Spesifikasi Kebutuhan Data dengan menggunakan class diagram, di mana diagram ini berfungsi untuk memperhalus desain dari obyek (use case) yang sudah dibuat ke dalam diagram data yang berisikan tentang skema dan hubungan antar tabel yang terbentuk dari data yang berjalan di atas sistem.

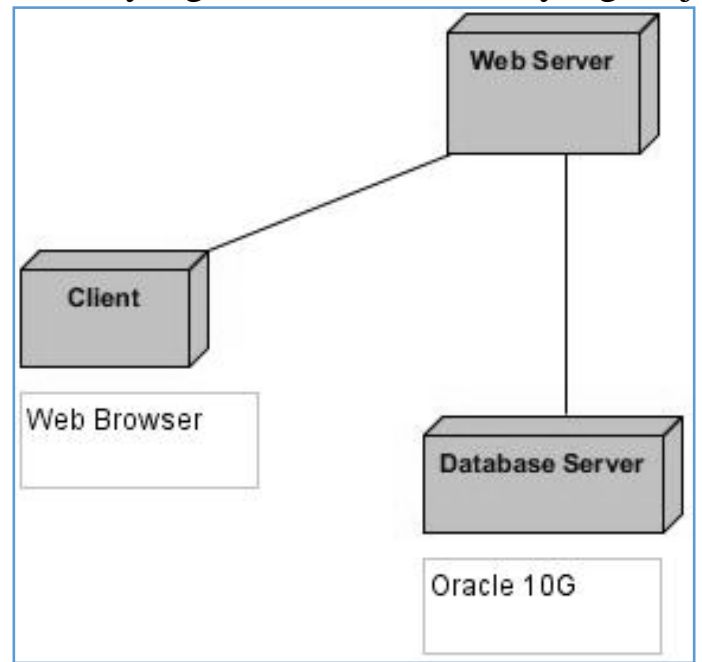

Gambar 3: Deployment Diagram Sistem Informasi Manajemen Dan Geografis Pemetaan Sumber Daya Air

Software Requirement Specification Sistem Informasi

Manajemen dan Geografis Pemetaan Sumber Daya Air 


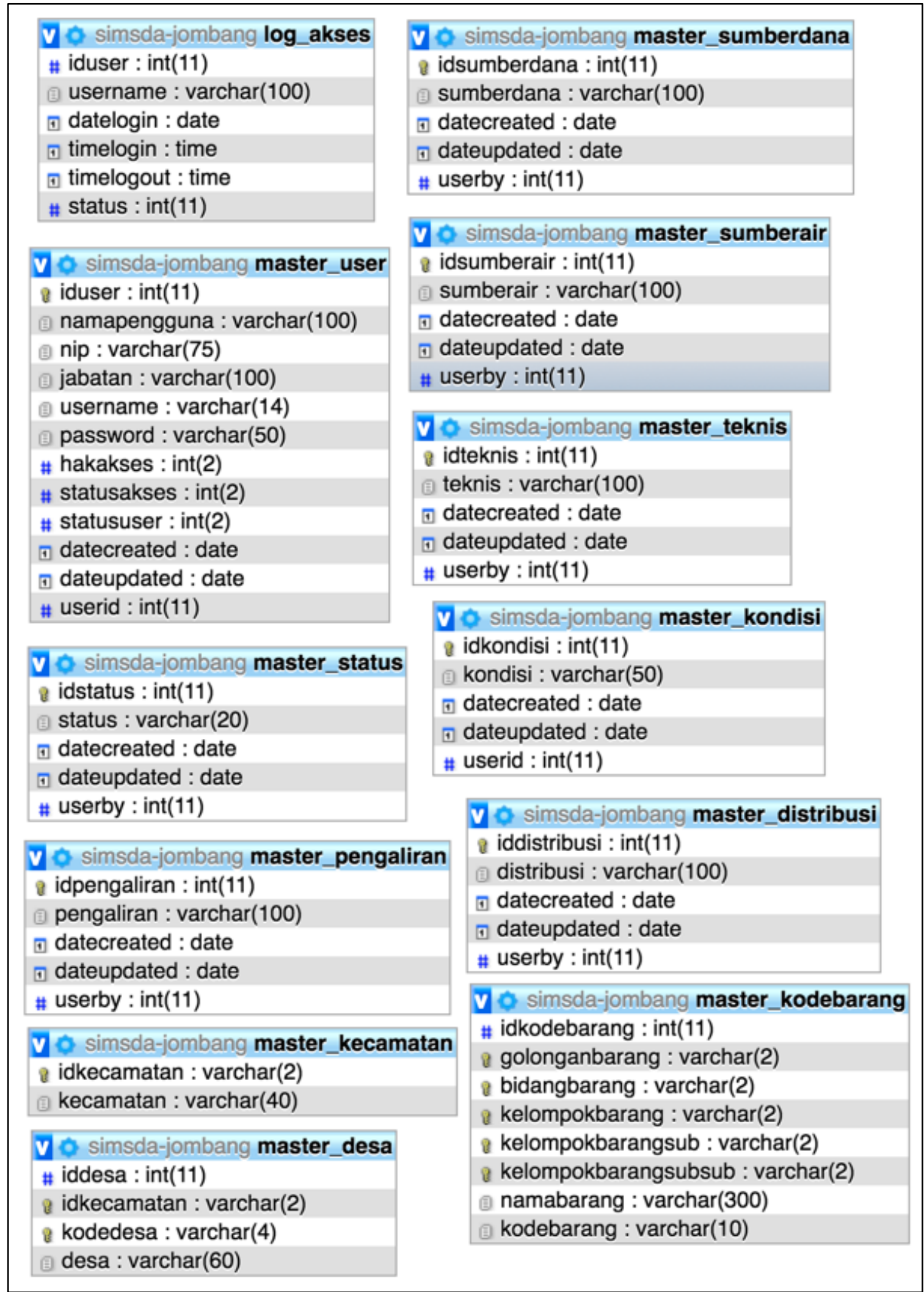

Gambar 2: Conceptual Data Model dari Sistem Informasi Manajemen Dan Geografis Pemetaan Sumber Daya Air

Software Requirement Specification Sistem Informasi

Manajemen dan Geografis Pemetaan Sumber Daya Air 


\section{d. Spesifikasi Kebutuhan Infrastruktur}

Diagram ini menjelaskan secara detail terakit gambaran bagaimana komponen sistem disebar dalam skema infrastruktur yang ada, skema tersebut adalah sebagai berikut:

Deployment diagram ini dibuat untuk menunjukkan semua node pada sistem, hubungan di antara sistem, dan proses yang akan dijalankan pada masing-masing node

- Node: Client

Client merupakan komputer yang digunakan oleh user untuk melakukan pengelolaan terhadap data perhitungan simulasi. Proses yang ada didalamnya adalah Web Browser

- Node: Web Server

Web Server merupakan computer yang menyediakan layanan web bagi client yang mengakses internet, di mana web server ini akan mengakses database untuk operasi yang melibatkan data-data pada database.

- Node: Database Server

Database Server merupakan komputer yang dipakai untuk menyediakan koneksi ke database dan mengauthentikasi web server dan tidak akan mengizikan melihat informasi atau menjalankan prosedur kecuali jika ia memiliki hak yang sesuai.

\section{KESIMPULAN}

\subsection{Kesimpulan}

Berdasarkan hasil implementasi dan pengujian terhadap Spesifikasi kebutuhan perangkat lunak yang sudah didokumentasikan adalah:

1. Analisa kebutuhan sudah di definisikan dan di petakan sesuai dengan fungsi dan kepemilikan sehingga deskripsi asumsi, batasan dan ketergantungan bisa di buat

2. Tabel analisa kebutuhan yang di definisikan sesuai dengan spesifikasi sistem yang sudah di gambar dalam use case diagram dan spesifikasi detail.

3. Untuk kebutuhan non fungsional sesuai dengan diagram pengembangan komponen infrastruktur yang ada pada deployment diagram

\subsection{Saran}

Saran untuk pengembangan dokumen ini adalah:

1. Dokumen yang di hasilkan dapat langsung digunakan untuk pembuatan Software Design Description.

2. Dokumen Software Requirement Specifiaction ini dapat digunakan sebagai dokumentasi pengembangan sistem informasi yang sudah sesuai dengan proses pengukuran pada tingkat pengembangan perangkat lunak.

\section{REFERENSI}

[1] Arifin, Zainul. 2003. Dasar-Dasar Manajemen Bank Syariah. Jakarta:Alvabet.

[2] Bassil, Youssef. 2012. A Simulation Model for the Waterfall Software Development Life Cycle. International Journal Of Engineering \& Technology (iJET). ISSN : 2049-3444. Vol2. No 5.

[3] Boehm B, Kitapci H., 2006, The WinWin approach : using a requirements negotiation tool for rationale capture and use. In : Dutoit A, McCall R, Mistrik, I, Paech B(eds) Rationale 
URL : https://jurnal.machung.ac.id/index.php/kurawal

Management in Software Engineering, Springer

[4] Dewan Syariah Nasional MUI, dalam Fatwa Dewan Syari'ah Nasional No. 21/ DSNMUI/IX/2001.

[5] Hartono, Jogiyanto. 2009. Teori Portofolio dan Analisis Investasi Edisi Keenam. Yogyakarta:BPFE Yogyakarta.

[6] Kendal, K dan Kendall, J. 2005. Systems Analysis and Design $6^{\text {th }}$ Edition. Pearson International Edition. Prentice Hall

[7] Software Engineering Standards Committee of the IEEE Computer Society, 1998, IEEE 830-1998 Recommended Practice for Software Requirements Specifications, The Institute of Electrical and Electronics Engineers, Inc.

[8] http://www.islamedia.web.id/2011/12/sekilas-tentang-haji-indonesia.html, diakses tanggal 3 Maret 2012.

[9] Whitten, Jeffery, L., etc, 2004, Systems Analysis and Design Methods, The McGraw-Hill Companies, Inc 